\title{
Unbalance Identification of Speed-Variant Rotary Machinery without Phase Angle Measurement
}

\author{
Cong Yue, ${ }^{1}$ Xingmin Ren, ${ }^{1}$ Yongfeng Yang, ${ }^{1}$ and Wangqun Deng ${ }^{2}$ \\ ${ }^{1}$ School of Mechanics, Civil Engineering and Architecture, Northwestern Polytechnical University, Xian 710072, China \\ ${ }^{2}$ China Aviation Dynamical Machinery Research Institute, Zhuzhou, Hunan 412002, China \\ Correspondence should be addressed to Xingmin Ren; renxmin@nwpu.edu.cn
}

Received 9 March 2015; Revised 15 May 2015; Accepted 18 May 2015

Academic Editor: Reza Jazar

Copyright (c) 2015 Cong Yue et al. This is an open access article distributed under the Creative Commons Attribution License, which permits unrestricted use, distribution, and reproduction in any medium, provided the original work is properly cited.

\begin{abstract}
As rotary mechanical structure becomes more complicated, difficulty arises in receiving prime correction mass and optimum balancing plane efficiently. An innovative modal balancing process for estimating the residual unbalance from different equilibrium plane of complex flexible rotor system is presented. The method is based on a numerical approach with modal ratio among measurement points (MRMP) coefficient and triple phase method (TPM). The veracity of calculation result is verified by an academic rotor model. The latter study in this paper is subsequently put forward through a power turbine rotor modeled by finite element method. Simulation results show that proper equilibrium plane performs commendably in recognizing residual unbalance and reducing the vibration effect through the critical region. Moreover, the inherent unbalance recognized by experimental data from a turbine rotor with slender shaft is found to be in certain difference under different counterweight combination. Choosing suitable balancing planes will improve the accuracy of unbalance identification.
\end{abstract}

\section{Introduction}

Rotating machines are often slightly unbalanced due to manufacture inaccuracy and operation loss. It is generally recognized that unbalance force is the main source of rotor vibration. The fluctuation magnitude of oscillation caused by unbalance force is intense when angular acceleration grows rapidly. In this case, the unbalanced vibration analysis of flexible rotor passing through critical speed is an important issue at both low speed and high speed. As a result, the balancing of flexible rotors is one of the pivotal techniques for speed-variant rotating machinery in modern industry.

Conventional balance methods, for example, modal balancing method [1-3], the influence coefficient method [4, 5], and the unified approach $[6,7]$, have been well exploited in the numerical domain. Vania and Pennacchi [8] developed some methods by measuring the accuracy of balancing techniques to identify unbalance in rotating machines. Sinha et al. [9] estimated mass unbalance and misalignment of a rotating machine from the process of acceleration and deceleration. Sudhakar and Sekhar [10] presented two different approaches applied for the identification of unbalance fault in a rotor system. Unbalance fault was identified using proposed methods by measuring transverse vibrations at only one location. Whalley and Abdul-Ameer [11] investigated a general approach for shaft-rotor analysis and design, enabling both computation of the transient and frequency response performance. A new concept of modal balancing technique which firstly adopts MRMP coefficient is proposed for flexible rotor operating between the first two critical speeds [12].

Generally speaking, rotor structure becomes diversified and complicated with the extensive application of flexible rotor. Confirming appropriate position of equilibrium plane turns to be the crucial factor before applying available balance method [13, 14]. In the recent research, Sève et al. [15] reviewed survey work on the predicted unbalance responses between rotating and stator parts of a rotary compressor. The comparison permits minimizing vibration transmission through pipes and grommets. Chatzisavvas and Dohnal [16] achieved unbalance identification under different unbalance masses and balancing planes for a test rig.

The contribution of this paper consists in the balancing of a power turbine rotor with known initial unbalance mass which is mounted on foregone combinations of balancing 
planes. The objective is to survey and compare the residual oscillation levels of this dynamic model during accelerating process by an extension application of the MRMP coefficient and TPM. The proposed scheme uses transfer matrix method (TMM) and finite elements method (FEM) to obtain the motion equation. An industrial application permits comparing the measured unbalance responses, which is conducive in confirming appropriate combination of balancing planes and reducing the required balancing information.

\section{Balancing Theory}

2.1. Modal Balancing and MRMP Coefficient. To obtain accurate correction mass, the employed basic theory of modal balancing $[17,18]$ and MRMP coefficient will be first reviewed. For main notations, refer to Appendix A. Considering an isotropic flexible rotor system with arbitrary distributed mass, the characteristic modal function $\phi_{n}(z), n=1,2, \ldots$, can be obtained when the geometrical features and physical parameters of the system are given. The orthogonality condition between any two modes is a prerequisite, which is defined as

$$
\int_{0}^{l} m(z) \phi_{n}(z) \phi_{k}(z) \mathrm{d} z= \begin{cases}0, & n \neq k \\ N_{n}, & n=k\end{cases}
$$

in which $N_{n}$ is the $n$th generalized mass. According to the orthogonal principal, the distribution of initial unbalance mass eccentricity of shaft $\mu(z)$ can be stated as

$$
u(z)=\sum_{n=1}^{\infty} u_{n} e^{i \delta_{n}} \varphi_{n}(z) .
$$

With the main modal orthogonality theory, the dynamic deflection $R(z, t)$ can be expressed as

$$
R(z, t)=e^{i \omega t} \sum_{n=1}^{\infty} \frac{\gamma_{n}^{2}}{1-\gamma_{n}^{2}} u_{n} e^{i \delta_{n}} \varphi_{n}(z)
$$

in which the ratio of $n$th revolving speed $\gamma_{n}=\omega / \omega_{c n}$. Figure 1 shows the first three modal shapes of general flexible rotor system. Equation (3) shows that the deflections of the rotor are weighted sum of infinite order $\phi_{n}(z)$ multiplying coefficient and it will have the same shape as those of the $n$th mode when the rotor runs at the $n$th critical speed. For the $n$th principal mode, the ratio of modal displacement at location $z=z_{i}(i=1,2,3, \ldots)$ is called the MRMP coefficient, which is defined as

$$
\lambda_{i, j}^{n}=\frac{\phi_{n}\left(z_{i}\right)}{\phi_{n}\left(z_{j}\right)}=\nu \frac{R_{i n}(z, t)}{R_{j n}(z, t)} \quad j \neq i .
$$

The application of MRMP coefficient makes it possible to balance the first two critical speeds simultaneously.

2.2. Triple Phase Method. When simulating the whirling response of intricate rotating system, the prediction on the magnitude and distribution of unbalance mass is beneficial

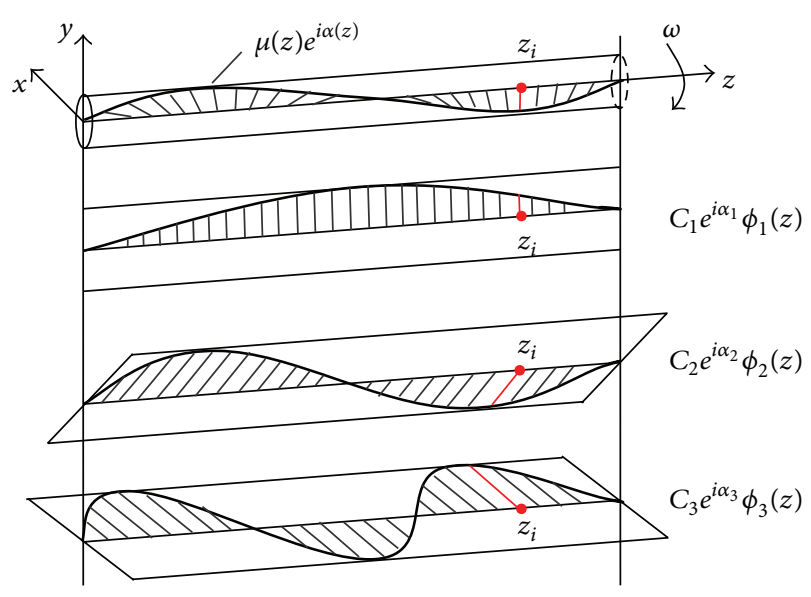

FIGURE 1: The general first three modal shapes of rotor-bearing system.

to determine the identification of initial unbalance and counterbalance effect. The proposed method is concerned with the case in which phase measurement instruments cannot be applied directly, so that the scheme of TPM is performed. The relationship of a linear shaft-bearing system in each balancing plane is

$$
R_{k}(z, t) e^{i \alpha_{k}}-R_{0}(z, t) e^{i \alpha_{0}}=\gamma T e^{i\left(\theta_{k}+\beta\right)}, \quad k=1,2,3,
$$

where unbalanced azimuths are all dubious while $R_{k}$ and $R_{0}$ are concerned. Another run test turns $\left(\theta_{k}+\alpha_{0}\right)$ degree clockwise; (5) is determined by

$$
R_{k}(z, t) e^{i\left(\alpha_{k}-\alpha_{0}-\theta_{k}\right)}-R_{0}(z, t) e^{-i \theta_{k}}=\gamma T e^{i\left(\beta-\alpha_{0}\right)} .
$$

Rotating $180^{\circ}$ and symmetry transforming with $x$ axis, (6) can be written as

$$
R_{k}(z, t) e^{i\left(\pi+\alpha_{0}+\theta_{k}-\alpha_{k}\right)}+R_{0}(z, t) e^{i \theta_{k}}=\gamma T e^{i\left(\pi+\alpha_{0}-\beta\right)} .
$$

$R$ and $\left(\pi+\alpha_{0}-\beta\right)$ are the magnitude and the azimuth of unbalance mass angle under the corresponding vibration mode, respectively. When $R_{k}=0$, correction trial weight $\mathbf{W}$ at rotating speed of $\omega$ can be expressed as

$$
\mathbf{W}=-\frac{R_{0}(z, t)}{\gamma e^{i\left(\beta-\alpha_{0}\right)}} .
$$

Figure 2 presents the recognition principle of mass unbalance by TPM. The feasibility and procedure which obtained correction mass will be discussed in the next section, in which an academic rotor system is used to inspect the process of decomposing and calculating the modal components of transient unbalance response correspondingly. In addition, a turbine rotor system is put forward to verify the applicability of this modified balancing procedure.

\section{Balancing Procedure}

3.1. Academic Rotor Model. A typical model of rotating shaft including the gyroscopic effect, the effects of transverse and 


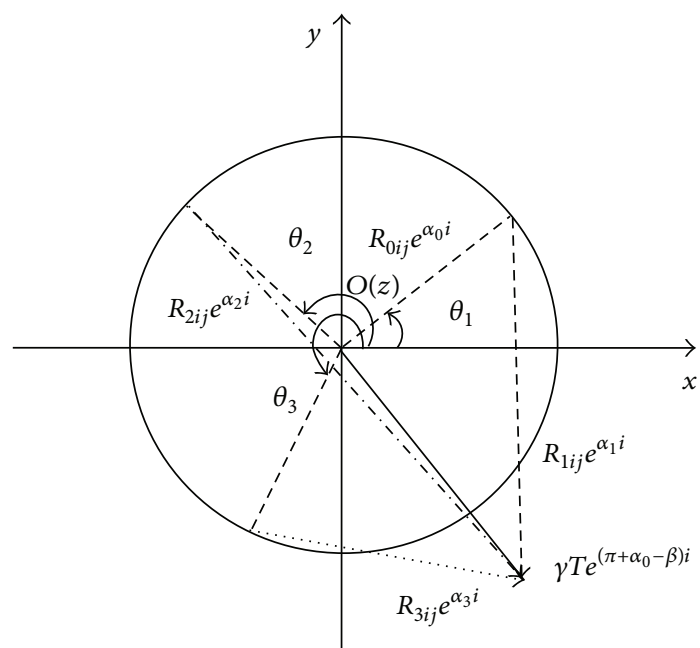

FIGURE 2: Schematic diagram of triple phase method.

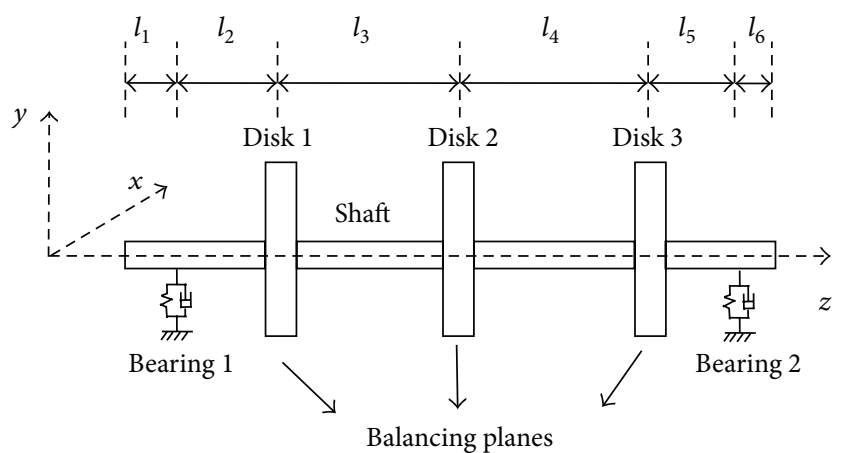

FIGURE 3: Universal rotor-bearing rotor model.

rotational inertia, the effects of shear and bending deformations, and centrifugal force is presented. The disks have both rotational inertia and gyroscopic inertia. The linearity hypothesis is defined as follows: the whole vibration response due to influence of trial weights on different planes is equal to the sum of individual vibration responses caused by each trial weight, which is the precondition where unbalance force is the major fault; meanwhile, the lumped force and supporting action all should remain stable. The configuration of the rotor-bearing system and the locations of the three unbalances are shown in Figure 3. The main parameters of this model are presented in Appendix B. The transient unbalance differential equation of motion established by TMM is expressed as

$$
\mathbf{M} \ddot{\mathbf{U}}+\left(\mathbf{C}(\omega)+\mathbf{C}_{S}\right) \dot{\mathbf{U}}+\mathbf{K}_{B} \mathbf{U}=\mathbf{f}(t) .
$$

$\mathbf{U}$ is the vector containing all the degrees of freedom (d.o.f.) and each node has two lateral displacements and two associated rotations. $\mathbf{M}$ stands for the classical mass matrix of balancing planes, $\mathbf{C}(\omega)$ indicates the nonsymmetric gyroscopic matrix, $\mathbf{C}_{S}$ is the damping matrix associated with rotational inertia, and $\mathbf{K}_{B}$ presents the equivalent stiffness matrix related to the shaft and bearing. At location $z=z_{i}$, the component of the unbalance force vector $\mathbf{f}(t)$ is created by the unbalance masses $m_{i} e_{i}$ at the phase angle $\varphi_{0 i}$ as follows:

$$
\begin{array}{r}
F_{x, i}=m_{i} e_{i} \dot{\varphi}^{2} \cos \left(\omega t+\varphi_{0 i}\right)+m_{i} e_{i} \ddot{\varphi} \sin \left(\omega t+\varphi_{0 i}\right), \\
F_{y, i}=m_{i} e_{i} \dot{\varphi}^{2} \sin \left(\omega t+\varphi_{0 i}\right)-m_{i} e_{i} \ddot{\varphi} \cos \left(\omega t+\varphi_{0 i}\right), \\
i=1,2, \ldots .
\end{array}
$$

This type of model permits the computation of transient whirl response for all balancing planes necessary balancing the rotary machine. The transient unbalance response is predicted through a modal theory and the solution of a linear system for each rotating speed $\omega$.

3.2. Decomposition of Unbalances and Responses. To balance the flexible rotor showed in Figure 3, only the first three modal components of unbalance will be considered if the influence of higher modal components can be neglected. Supposing that the test weights $\mathbf{T}_{1}, \mathbf{T}_{2}$, and $\mathbf{T}_{3}$ (text weights need not be orthogonal, so prior knowledge of the modal shape of the rotor-bearing system is not necessary for the calculation of the test weights) are added on the balancing planes and accelerate over the first three-order critical speeds, the first three-order modal components $\left(\mathbf{W}_{11}, \mathbf{W}_{21}, \mathbf{T}_{31}\right)$, $\left(\mathbf{W}_{12}, \mathbf{W}_{22}, \mathbf{W}_{32}\right)$, and $\left(\mathbf{W}_{13}, \mathbf{W}_{23}, \mathbf{W}_{33}\right)$ can be decomposed into

$$
\mathbf{W}=\left[\mathbf{W}_{j i}\right], \quad i, j=1,2,3 .
$$

The first three characteristic modal functions $\phi_{n}(z)$ can be presented as

$$
\begin{aligned}
\boldsymbol{\delta}_{1} & =\left[\boldsymbol{\varphi}_{2}(z), \boldsymbol{\varphi}_{3}(z), \boldsymbol{\varphi}_{1}(z)\right]^{\mathrm{T}}, \\
\boldsymbol{\delta}_{2} & =\left[\boldsymbol{\varphi}_{3}(z), \varphi_{1}(z), \boldsymbol{\varphi}_{2}(z)\right]^{\mathrm{T}}
\end{aligned}
$$

in which

$$
\boldsymbol{\varphi}_{i}(z)=\left[\phi_{i}\left(z_{1}\right), \phi_{i}\left(z_{2}\right), \phi_{i}\left(z_{3}\right)\right] .
$$

Each mode shape should satisfy the following orthogonal conditions with simultaneous equations (1) and (12)

$$
\mathbf{W} \cdot \boldsymbol{\delta}=\mathbf{0} .
$$

Substituting (14) into (15), the decomposition trial weights can be rewritten as in the following formula:

$$
\begin{aligned}
Z & =\lambda_{1,2}^{1} \lambda_{1,2}^{2} \lambda_{1,3}^{1} \lambda_{1,3}^{3}-\lambda_{1,2}^{1} \lambda_{1,2}^{3} \lambda_{1,3}^{1} \lambda_{1,3}^{2}-\lambda_{1,2}^{1} \lambda_{1,2}^{2} \lambda_{1,3}^{1} \lambda_{1,3}^{3}+\lambda_{1,2}^{2} \lambda_{1,2}^{3} \lambda_{1,3}^{1} \lambda_{1,3}^{2}+\lambda_{1,2}^{1} \lambda_{1,2}^{3} \lambda_{1,3}^{2} \lambda_{1,3}^{3}-\lambda_{1,2}^{1} \lambda_{1,2}^{3} \lambda_{1,3}^{1} \lambda_{1,3}^{3}, \\
\mathbf{w}_{11} & =\frac{\left(\lambda_{1,2}^{2} \lambda_{1,3}^{3}-\lambda_{1,2}^{3} \lambda_{1,3}^{2}\right)\left(\lambda_{1,2}^{1} \lambda_{1,3}^{1} \mathbf{T}_{1}+\lambda_{1,3}^{1} \mathbf{T}_{2}+\lambda_{1,2}^{1} \mathbf{T}_{3}\right)}{Z},
\end{aligned}
$$




$$
\begin{aligned}
& \mathbf{W}_{12}=\frac{\left(\lambda_{1,2}^{3} \lambda_{1,3}^{1}-\lambda_{1,2}^{1} \lambda_{1,3}^{3}\right)\left(\lambda_{1,2}^{2} \lambda_{1,3}^{2} \mathbf{T}_{1}+\lambda_{1,3}^{2} \mathbf{T}_{2}+\lambda_{1,2}^{2} \mathbf{T}_{3}\right)}{Z}, \\
& \mathbf{W}_{13}=\frac{\left(\lambda_{1,2}^{1} \lambda_{1,3}^{2}-\lambda_{1,2}^{2} \lambda_{1,3}^{1}\right)\left(\lambda_{1,2}^{3} \lambda_{1,3}^{3} \mathbf{T}_{1}+\lambda_{1,3}^{3} \mathbf{T}_{2}+\lambda_{1,2}^{3} \mathbf{T}_{3}\right)}{Z}, \\
& \mathbf{W}_{21}=\frac{\left(\lambda_{1,3}^{2}-\lambda_{1,3}^{3}\right)\left(\lambda_{1,2}^{1} \lambda_{1,2}^{2} \lambda_{1,2}^{3} \lambda_{1,3}^{1} \mathbf{T}_{1}+\lambda_{1,2}^{2} \lambda_{1,2}^{3} \lambda_{1,3}^{1} \mathbf{T}_{2}+\lambda_{1,2}^{1} \lambda_{1,2}^{2} \lambda_{1,2}^{3} \mathbf{T}_{3}\right)}{Z}, \\
& \mathbf{W}_{22}=\frac{\left(\lambda_{1,3}^{3}-\lambda_{1,3}^{1}\right)\left(\lambda_{1,2}^{1} \lambda_{1,2}^{2} \lambda_{1,2}^{3} \lambda_{1,3}^{2} \mathbf{T}_{1}+\lambda_{1,2}^{1} \lambda_{1,2}^{3} \lambda_{1,3}^{2} \mathbf{T}_{2}+\lambda_{1,2}^{1} \lambda_{1,2}^{2} \lambda_{1,2}^{3} \mathbf{T}_{3}\right)}{Z}, \\
& \mathbf{W}_{23}=\frac{\left(\lambda_{1,3}^{1}-\lambda_{1,3}^{2}\right)\left(\lambda_{1,2}^{1} \lambda_{1,2}^{2} \lambda_{1,2}^{3} \lambda_{1,3}^{3} \mathbf{T}_{1}+\lambda_{1,2}^{1} \lambda_{1,2}^{2} \lambda_{1,3}^{3} \mathbf{T}_{2}+\lambda_{1,2}^{1} \lambda_{1,2}^{2} \lambda_{1,2}^{3} \mathbf{T}_{3}\right)}{Z}, \\
& \mathbf{W}_{31}=\frac{\left(\lambda_{1,2}^{3}-\lambda_{1,2}^{2}\right)\left(\lambda_{1,2}^{1} \lambda_{1,3}^{1} \lambda_{1,3}^{2} \lambda_{1,3}^{3} \mathbf{T}_{1}+\lambda_{1,3}^{1} \lambda_{1,3}^{2} \lambda_{1,3}^{3} \mathbf{T}_{2}+\lambda_{1,2}^{1} \lambda_{1,3}^{2} \lambda_{1,3}^{3} \mathbf{T}_{3}\right)}{Z}, \\
& \mathbf{W}_{32}=\frac{\left(\lambda_{1,2}^{1}-\lambda_{1,2}^{3}\right)\left(\lambda_{1,2}^{2} \lambda_{1,3}^{1} \lambda_{1,3}^{2} \lambda_{1,3}^{3} \mathbf{T}_{1}+\lambda_{1,3}^{1} \lambda_{1,3}^{2} \lambda_{1,3}^{3} \mathbf{T}_{2}+\lambda_{1,2}^{2} \lambda_{1,3}^{1} \lambda_{1,3}^{3} \mathbf{T}_{3}\right)}{Z}, \\
& \mathbf{W}_{33}=\frac{\left(\lambda_{1,2}^{1}-\lambda_{1,2}^{2}\right)\left(\lambda_{1,2}^{3} \lambda_{1,3}^{1} \lambda_{1,3}^{2} \lambda_{1,3}^{3} \mathbf{T}_{1}+\lambda_{1,3}^{1} \lambda_{1,3}^{2} \lambda_{1,3}^{3} \mathbf{T}_{2}+\lambda_{1,2}^{3} \lambda_{1,3}^{1} \lambda_{1,3}^{2} \mathbf{T}_{3}\right)}{Z} .
\end{aligned}
$$

Equation (9) is the theoretical basis for decomposing the modal unbalances and responses. Reference [12] has presented the availability of MRMP coefficient with the first two low modal unbalances. In this condition, we assume that the balancing and measuring planes overlap together to reduce the computational complexity when applying this new balancing method to higher critical speeds. The influence of modal components higher than the order of the operating speed is negligible; only the first $i$ modal components are considered. The rotor-bearing system is modeled to calculate the modal function by TMM and only measures the vibrations in balancing planes.

Here, the test trial weights of each mode shape have been disassembled and decomposed correspondingly. In this method, prior knowledge of initial unbalanced azimuth is not necessary.

Step one consists in choosing balancing planes, where the correction masses should be located. Target planes are used to observe the vibration level during accelerating process. The efficiency of the balancing depending on the position and number of target planes is the same with recognition accuracy of the first three critical vibration responses, which must be identified as representative as much as possible. The balancing processes are listed below.

(1) The first test runs without trial weights to simulate the initial unbalances: $\mathbf{T}_{0 i}$ at plane $i$. Then the rotor original vibrations are measured as $R_{0 i j}$ for $j$ th critical speed.

(2) MRMP coefficient calculation is as follows. The six MRMP coefficients are obtained by (4). In this step, only one run test is necessary for the rotor which works within the third critical speed.

(3) The test weights are put on three balancing planes in the next three test runs with $\mathbf{T}_{1}-\mathbf{T}_{3}$ and counterclockwise rotation in directions $0^{\circ}, 90^{\circ}$, and $240^{\circ}$, respectively. Rotor vibrations are measured in each run test, recorded as $R_{1 i j}, R_{2 i j}$, and $R_{3 i j}$. The test weights are taken off after each run test.

(4) Influence coefficients $\mathbf{I}_{n}$ on balancing plane under each order are calculated by (4) and (8).

(5) According to the distribution and reassembling of each trial weight component $\mathbf{W}_{i j}$ in (15), the eccentric masses will be well corrected for the whole rotorbearing system. Tables 1 and 2 list test weights added in above process. Tables 3 and 4 show the determined correction weights.

Above balancing objective takes account of the first three modal components of unbalance. In this method, only amplitude information by 4 run-up tests is required. The measuring condition is suitable for the field balancing. The next sections will show the application in the balancing simulation and experiment.

3.3. Numerical Simulations. Preliminary investigations show that the unbalance response of the academic isotropic rotor model exhibits three critical speeds within 0-2600 r.p.m. speed range. The target planes are chosen depending on the balancing criteria of rotor system. Balancing speeds selected 
TABLE 1: Trail weights for the first three-order balancing.

\begin{tabular}{lccc}
\hline $\begin{array}{l}\text { Trial weights } \\
\left(\mathrm{g} \cdot \mathrm{cm} \angle^{\circ}\right)\end{array}$ & Plane 1 & Plane 2 & Plane 3 \\
\hline Run test 1 & $\mathbf{T}_{1}=88.2 \angle 66$ & $\mathbf{T}_{2}=70.1 \angle 27$ & $\mathbf{T}_{3}=70.1 \angle 166$ \\
Run test 2 & $\mathrm{T}_{1}=14.4 \angle 97$ & $\mathrm{~T}_{2}=70.1 \angle 93$ & $\mathrm{~T}_{3}=21.0 \angle 265$ \\
Run test 3 & $\mathrm{T}_{1}=75.7 \angle 11$ & $\mathrm{~T}_{2}=7.4 \angle 240$ & $\mathbf{T}_{3}=55.5 \angle 92$ \\
\hline
\end{tabular}

TABle 2: Trail weights for the first two-order balancing.

\begin{tabular}{lccc}
\hline $\begin{array}{l}\text { Trial weights } \\
\left(\mathrm{g} \cdot \mathrm{cm} \angle{ }^{\circ}\right)\end{array}$ & Plane 1 & Plane 2 & Plane 3 \\
\hline Run test 1 & $\mathbf{T}_{1}=88.2 \angle 66$ & $\mathbf{T}_{2}=36.7 \angle 60$ & $\mathbf{T}_{3}=70.1 \angle 166$ \\
Run test 2 & $\mathbf{T}_{1}=14.4 \angle 97$ & $\mathbf{T}_{2}=36.7 \angle 60$ & $\mathbf{T}_{3}=21.0 \angle 265$ \\
Run test 3 & $\mathbf{T}_{1}=75.7 \angle 11$ & $\mathbf{T}_{2}=36.7 \angle 60$ & $\mathbf{T}_{3}=55.5 \angle 92$ \\
\hline
\end{tabular}

in the operating speed range of $0-2800$ r.p.m. contain the resonance frequencies of the first three modes.

Tables 1 and 2 present the main parameters of balancing correction masses calculated for each balancing plane by MRMP coefficient. Displacements at disks present the balancing efficiency and are compared with the transient response under initial unbalance mass, Figure 4 . The rotor vibration accelerating throughout the specific speed range has been effectively reduced by proposed balancing procedure. Balancing result also shows that the first two modals have been well balanced even if there are multiunbalance masses (Figures 4(d) $-4(\mathrm{f})$ ).

\section{Application to Power Turbine Rotor Model}

4.1. Problem Description. In this section, the balancing procedure presented above is applied to an industrial flexible rotor. In this case, a linear power turbine rotor model is presented. The transmission elements and rotating parts are composed of a flexible shaft which is distributed with six lumped masses, four rigid bearings, two hollow turbine disks, three lug bosses, and a branch structure. The system is capable of running in a variable rotating speed range within $0-2400 \mathrm{rad} / \mathrm{s}$. Thus, the vibration condition must be reduced by sufficient balancing throughout the time-various spindle speed.

4.2. Finite Element Model. In the FE model, the rotor-shaft is considered as a slender shaft while balancing lug bosses and disks are assumed to be rigid on its position. The bearings are modeled with bearing elements whose parameters depend on variable speed. The axis symmetric sketch of the FE model is shown in Figure 5. Each node has four d.o.f., including two lateral displacements and two associated rotations.

The power turbine rotor (driving shaft part) is modeled with 41-node beam-shaft elements (from nodes 1 to 41) and 2 one-node disk elements at nodes 7 and 9. The four bearings are indicated as bearing 1 (node 2), bearing 2 (node 40 ), bearing 3 (node 41 ), and bearing 4 (node 10). The two squeeze film dampers are modeled with an equivalent additional element with no mass (assigned to nodes 3 and 8 ), their properties being taken into account by an additional damping, and stiffness locates at the bearing position. Six lumped masses (nodes 14-17, 25, and 29) are equivalent to stable external forces. The coefficient matrix follows the original oscillatory device described in $[19,20]$. The following motion equation contains the transient unbalance response of the turbine rotor:

$$
\mathbf{M} \ddot{\mathbf{q}}+(\mathbf{C}-\omega \mathbf{G}) \dot{\mathbf{q}}+\mathbf{K q}=\mathbf{Q}(t)
$$

with $\mathbf{q}$ being the displacement vector containing all the d.o.f. of the assembly, $\mathbf{M}$ and $\mathbf{C}$ being the classical mass and damping matrices, $\mathbf{G}$ being the nonsymmetric gyroscopic matrix, and $\mathbf{Q}(t)$ being the unbalance force vector created by the unbalance masses on three balancing lug bosses and two turbine disks such as (9).

4.3. Balancing. The balancing criteria are based on the minimization of the vibration level of the shaft and disks. In view of the structural characteristic and industrial requirement, it is necessary to keep three balancing planes at the lug bosses (nodes 4, 5, and 6) without phase measuring position. Initial unbalance masses exist at both disks and lug bosses. Figure 6 shows decomposition response of the three-dimensional shape mode before and after balancing to notarize credible applicability of imbalance recognition. 11 target planes located on the bosses, disks, bearings, and two ends are used in the balancing process. Considering the complexity of model, balancing efficiency depends on the target planes.

The transient unbalance response after balancing is successively presented and compared with the transient responses with initial unbalance mass. On the basis of the same balancing procedures shown in Section 3.2, the vibration levels of the shaft and turbine disks are satisfactory in the process of accelerating, especially in the first three critical speeds 800,1500 , and $2300 \mathrm{rad} / \mathrm{s}$. The first two-order vibration responses before and after correction by selecting different combination of equilibrium plane are shown in Figures 7 and 8 . High-speed balancing concerns the vibration levels of the bearing, lug boss, and disk. This simulation can be applied to compare the dissimilarity of balancing effect under different planes while the result shows that the combinations of nodes 4, 5 and nodes 4, 6 exhibit an expectant effectiveness.

\section{Experimental Simulation}

In this section, a power turbine rotor is used to validate the unbalance identification by different equilibrium plane. An illustration of the experimental apparatus is shown in Figure 9. Equilibrium position adopts the same serial number with FE model in Section 4. Three sensors distribute along the vertical axis and one along the horizontal axis for proximity probing the displacement of pilot.

In addition to some connected components and several simplified types of processing, physical dimensions of shaft and bearing elements are essentially consistent as the numerical model. The turbine rotor works under vacuum condition to reach operating speed (near 20000 r.p.m.). The average 


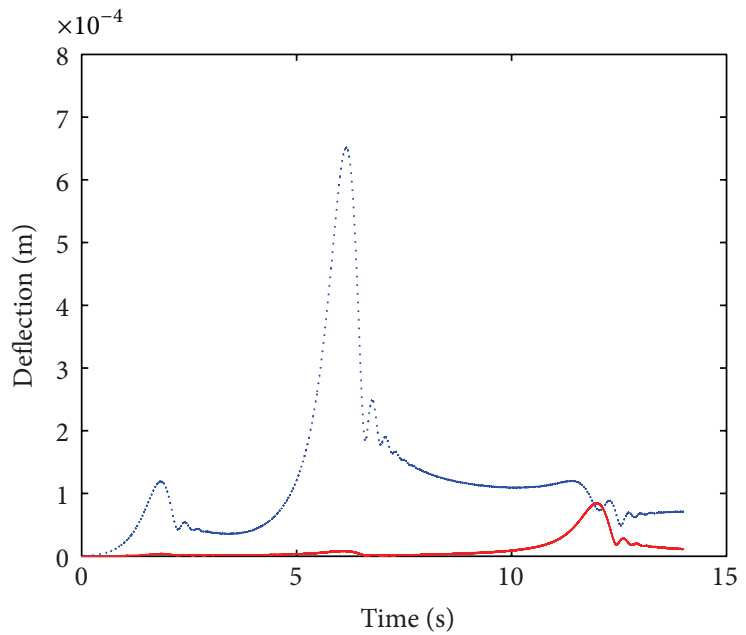

(a)

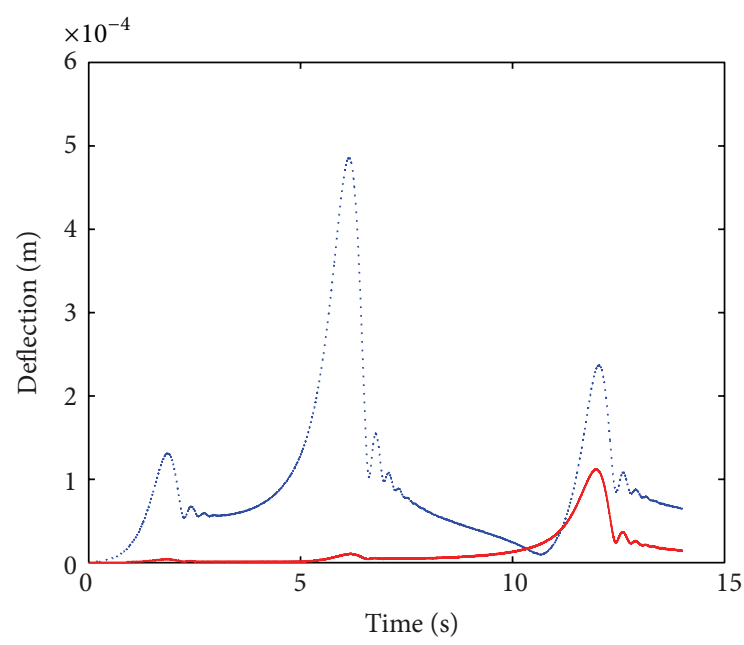

(c)

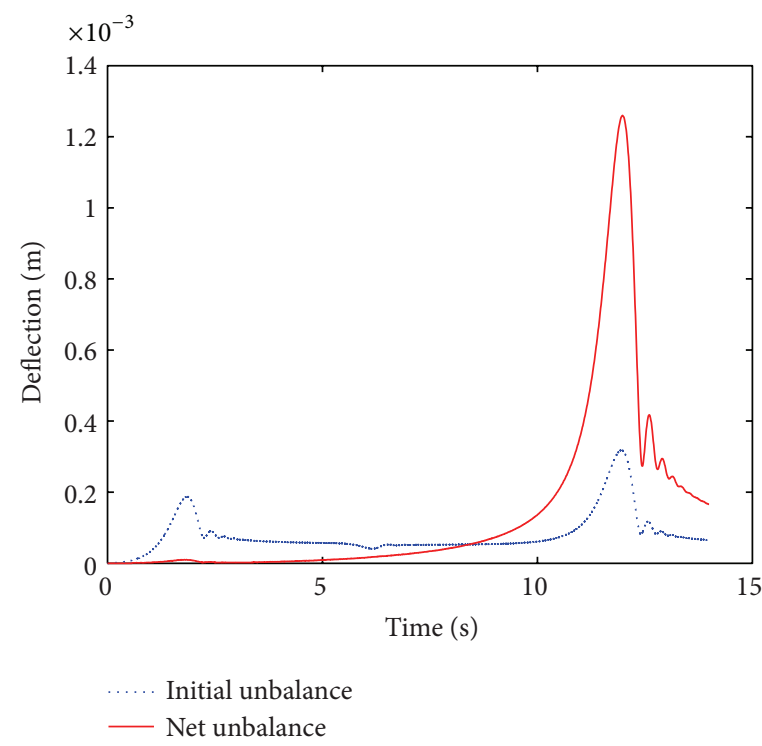

(e)

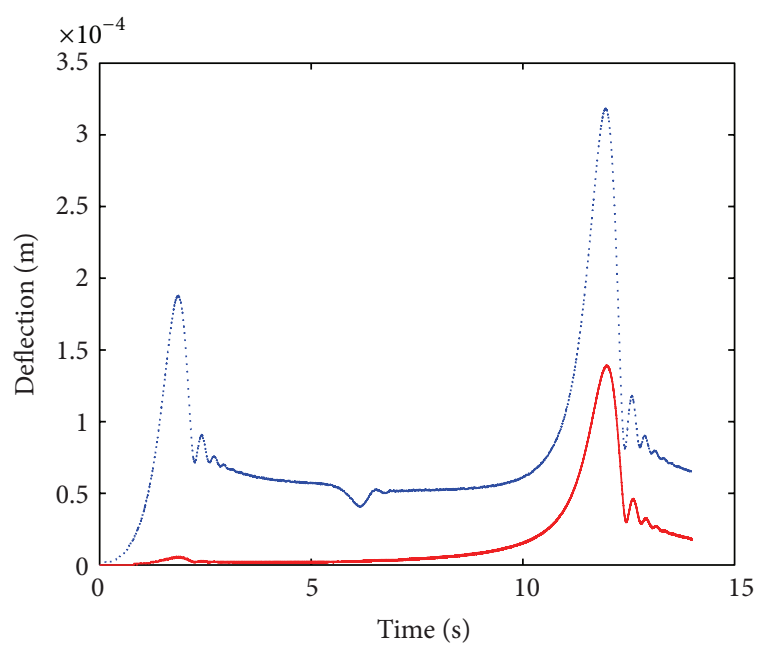

(b)

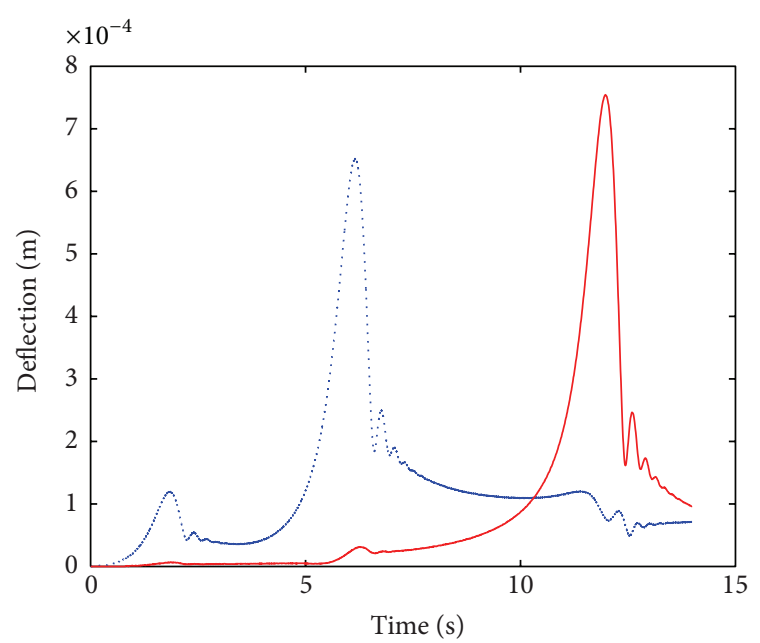

(d)

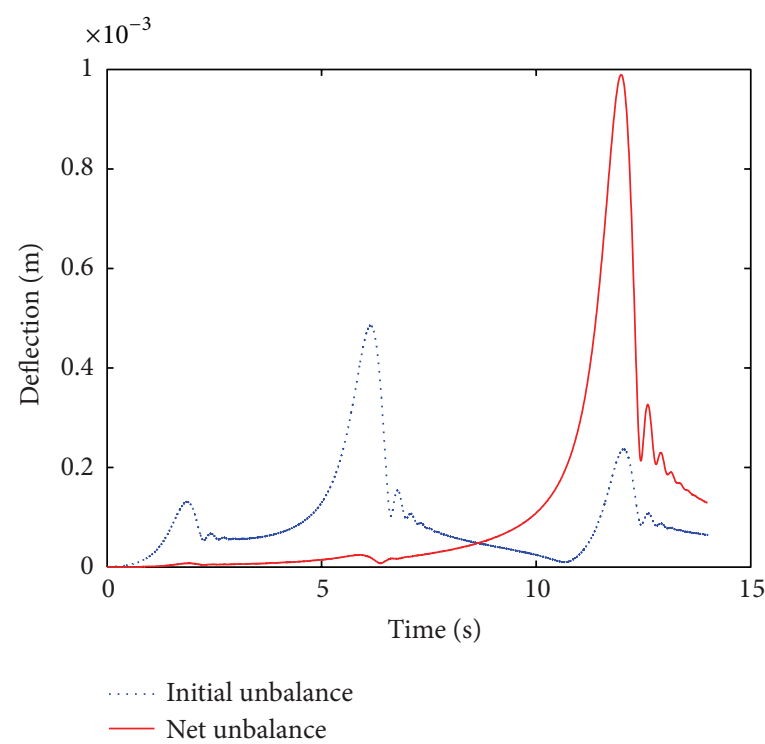

(f)

FIGURE 4: Lateral displacement responses versus speed of rotation with balancing $(-)$ and without balancing $(\cdots)$. First three-order (a) disk 1, (b) disk 2, and (c) disk 3; first two-order (d) disk 1, (e) disk 2, and (f) disk 3. 
TABLE 3: Unbalance correction for the first three critical speeds.

\begin{tabular}{lccc}
\hline Location & Balance plane 1 & Balance plane 2 & Balance plane 3 \\
\hline $\begin{array}{l}\text { Assumed value } \\
\left(\mathrm{g} \cdot \mathrm{cm} \angle^{\circ}\right)\end{array}$ & $51.45 \angle 45$ & $36.75 \angle 60$ & $29.41 \angle 144$ \\
$\begin{array}{l}\text { MRMP } \\
\text { coefficient }\end{array}$ & & $\lambda_{1,2}^{1}=0.6352, \lambda_{1,2}^{2}=-15.8131, \lambda_{1,2}^{3}=0.23$ & $\lambda_{1,3}^{1}=0.9085, \lambda_{1,3}^{2}=-1.3411, \lambda_{1,3}^{3}=0.3091$ \\
& & $\mathbf{W}_{21}=-45.99-22.54 i$ & $\mathbf{W}_{31}=3.16+0.29 i$ \\
$\begin{array}{l}\text { Correction mass } \\
\text { component }\end{array}$ & $\mathbf{W}_{11}=-7.53-30.93 i$ & $\mathbf{W}_{22}=5.70+1.21 i$ & $\mathbf{W}_{32}=-12.67-0.27 i$ \\
$\begin{array}{l}\text { Calculated value } \\
\left(\mathrm{g} \cdot \mathrm{cm} \angle^{\circ}\right)\end{array}$ & $\mathbf{W}_{12}=-15.11-39.61 i$ & $\mathbf{W}_{23}=26.72+9.93 i$ & $\mathbf{W}_{33}=10.21-2.12 i$ \\
& $\mathbf{W}_{13}=-4.14-35.84 i$ & $\mathbf{W}_{2}=32.71 \angle 240.3$ & $\mathbf{W}_{3}=31.68 \angle 319.5$ \\
\hline
\end{tabular}

TABLE 4: Unbalance correction for the first two critical speeds.

\begin{tabular}{lccc}
\hline Location & Balance plane 1 & Disk 2 & Balance plane 3 \\
\hline Assumed value $\left(\mathrm{g} \cdot \mathrm{cm} L^{\circ}\right)$ & $51.45 \angle 45$ & $36.75 \angle 60$ & $29.41 \angle 144$ \\
MRMP coefficient & $\lambda_{1,3}^{1}=\frac{R_{011}}{R_{031}}=0.9092, \lambda_{1,3}^{2}=-\frac{R_{012}}{R_{032}}=-1.3411$ & $\mathbf{W}_{21}=-20.74-54.15 i$ \\
Correction mass & $\mathbf{W}_{11}=-15.46-40.38 i$ & 0 & $\mathbf{W}_{22}=29.54-12.58 i$ \\
component & $\mathbf{W}_{12}=-32.49-13.83 i$ & 0 & $\mathbf{W}_{2}=42.50 \angle 282$ \\
Calculated value $\left(\mathrm{g} \cdot \mathrm{cm} \angle^{\circ}\right)$ & $\mathbf{W}_{1}=72.37 \angle 228$ & 0 \\
\hline
\end{tabular}

TABle 5: Trail weights added on node 5 in each run-up.

\begin{tabular}{lcccc}
\hline Run test 1 & Run test 2 & Run test 3 & Run test 4 & Run test 5 \\
\hline $0.35 \mathrm{~g}, 150^{\circ}$ & $+0.33 \mathrm{~g}, 0^{\circ}$ & $+0.30 \mathrm{~g}, 90^{\circ}$ & $+0.35 \mathrm{~g}, 180^{\circ}$ & $+0.32 \mathrm{~g}, 270^{\circ}$ \\
\hline
\end{tabular}

acceleration can only be obtained as the acceleration is manually controlled (about $13 \mathrm{rad} / \mathrm{s}^{2}$ ). The first two critical speeds are 7800 r.p.m. and 13200 r.p.m. Peak amplitude at 4810 r.p.m. is caused by resonance of coupling and transmission shaft.

Analysis data is collected for a set of 2 run tests for each run-up condition, which is to avoid accidental measurable error. Figure 10 shows instantaneous deflection response and Short Time Fourier Transform (STFT) diagram before and after tracking filtering at node 5 . The trail weight is added to the balanced rotor (Table 5: run test 1 is treated as initial unbalanced test; run tests $2-5$ are used for unbalance measurement), thus estimating correction mass from node 4 to node 6 , respectively. The correction masses obtained in the scheme from different balancing planes are listed in Table 6. It is evident that unbalance recognition has some inconsistencies, especially for the magnitude of unbalance on node 6 and the phase angle on node 4 . In addition to the above parts, the rest of unbalance recognition is basically consistent with theory result. This variation may ascribe to slight alteration of trail weights, structural complexity, and rheonomous acceleration.

\section{Conclusion}

As theoretical application to complex flexible rotor system, the modified balancing method described in the present work is appropriate to estimate residual unbalance of flexible rotor by only 4 run-up tests without specific rotating speed, prior knowledge of initial unbalance, and phase angle measurement. The whole balancing procedure on the integrated numerical approach can be used to reduce vibration level through accelerating speed in a reasonable range.

The information given by run-up experimental investigation can be treated as preliminary validation of the proposed method. Three balancing planes are used to estimate the effect of unbalance identification. Applying this balancing procedure in speed-variant rotary machinery makes it possible to identify residual unbalance from disparate balancing plane and minimizing vibration of transmission shaft.

\section{Appendices}

\section{A. Notation}

$\phi_{n}(z): n$th characteristic modal function

$\mu(z)$ : Distribution of initial mass unbalance eccentricity of shaft

$\omega_{c n}: n$th critical frequency

$\omega$ : Rotating speed

$\lambda_{i, j}^{n}: n$th modal MRMP coefficient between planes $i$ and $j$

$R_{\text {in }}(z, t): n$th modal dynamic deflection at plane $i$

$x, y$ : Transverse displacements along axes $x$ and $y$, respectively

$z$ : Location of the horizontal axis of the rotor-bearing system

$\mathrm{T}_{0 i}$ : Initial unbalance on balancing plane $i$

$\mathbf{T}_{i}$ : Trial weight on balancing plane $i$ 
TABLE 6: Correction masses recognition for turbine rotor at 7800 r.p.m.

\begin{tabular}{|c|c|c|c|c|}
\hline \multirow{2}{*}{ Position } & \multirow{2}{*}{ Run tests utilized } & \multicolumn{3}{|c|}{ Correction masses } \\
\hline & & Individual $\left(\mathrm{g},{ }^{\circ}\right)$ & Mean value $\left(\mathrm{g},{ }^{\circ}\right)$ & Percentage error $(\%, \%)$ \\
\hline \multirow{3}{*}{ Node 4} & $2,3,4$ & $0.4755,232.4$ & \multirow{3}{*}{$0.5112,220.4$} & \multirow{3}{*}{$46.1,46.9$} \\
\hline & $3,4,5$ & $0.5464,196.1$ & & \\
\hline & $2,4,5$ & $0.5118,232.6$ & & \\
\hline \multirow{3}{*}{ Node 5} & $2,3,4$ & $0.4573,175.3$ & \multirow{3}{*}{$0.4695,182.4$} & \multirow{3}{*}{$34.1,21.6$} \\
\hline & $3,4,5$ & $0.4658,182.6$ & & \\
\hline & $2,4,5$ & $0.4855,189.4$ & & \\
\hline \multirow{3}{*}{ Node 6} & $2,3,4$ & $0.5485,206.3$ & \multirow{3}{*}{$0.5520,193.4$} & \multirow{3}{*}{$57.7,28.9$} \\
\hline & $3,4,5$ & $0.5239,198.6$ & & \\
\hline & $2,4,5$ & $0.5836,175.3$ & & \\
\hline
\end{tabular}

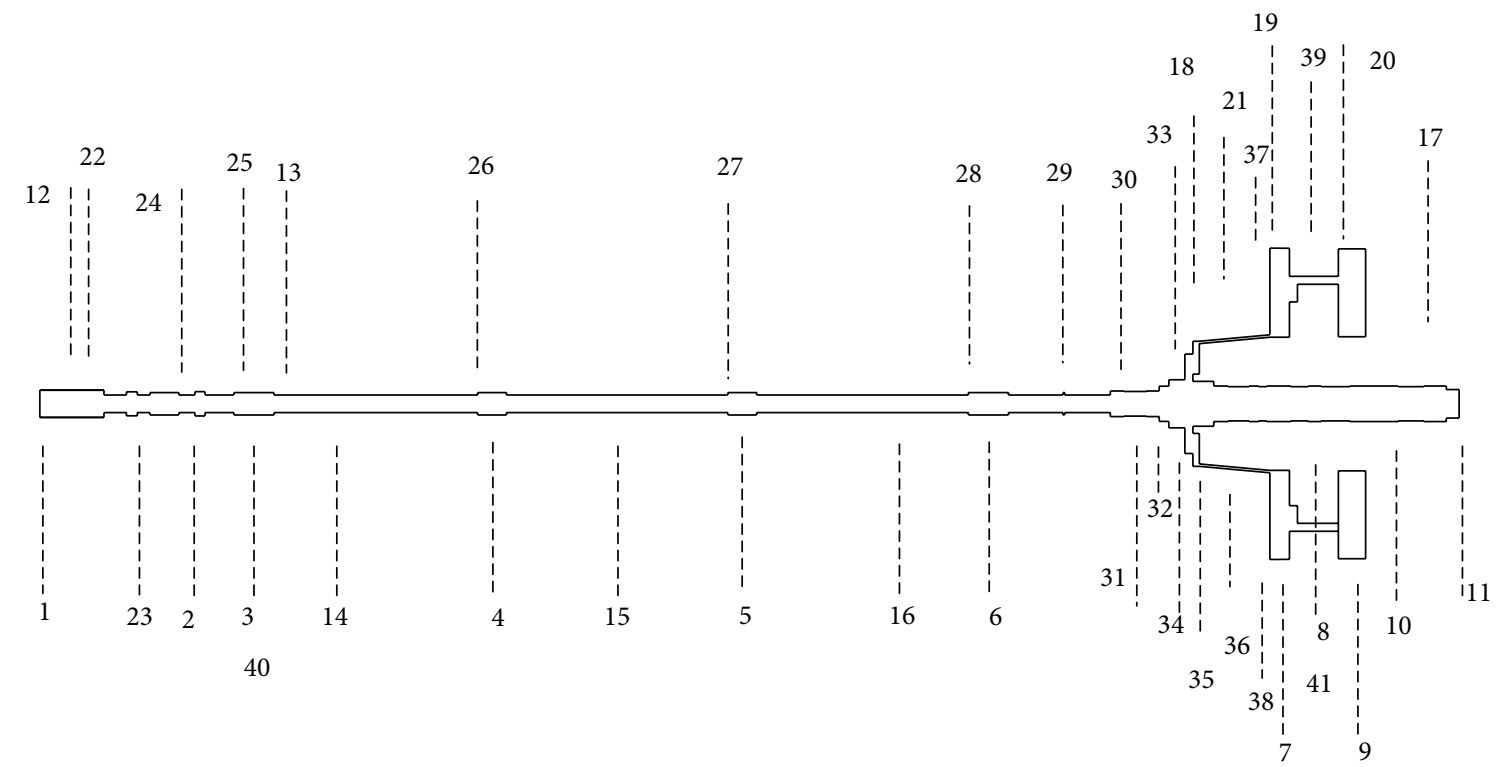

FIGURE 5: Finite element model of the power turbine rotor.

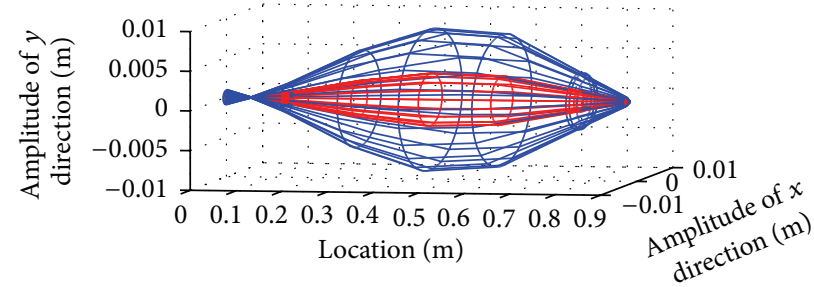

(a)

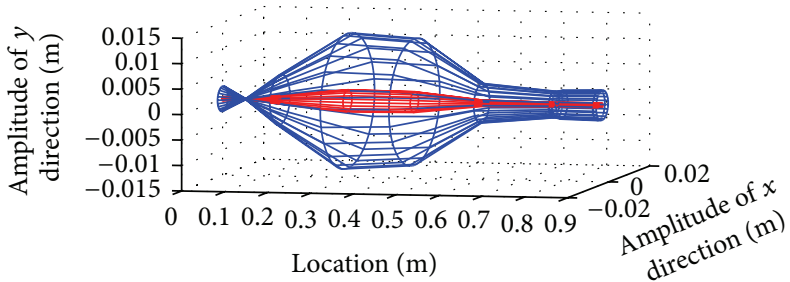

(b)

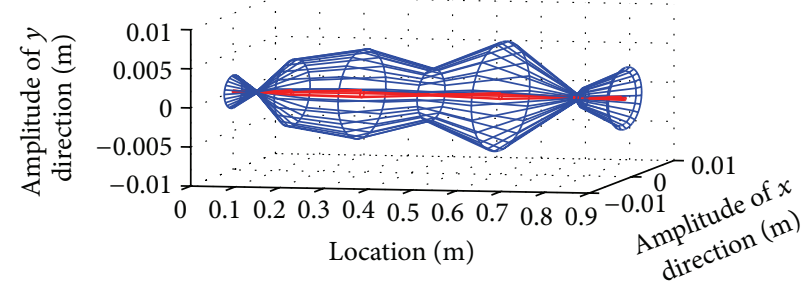

(c)

Figure 6: The lateral displacement response of the three-dimensional shape mode: without balancing (blue line) and with correction mass (red line); (a) the first critical speed of $800 \mathrm{rad} / \mathrm{s}$; (b) the second critical speed of $1500 \mathrm{rad} / \mathrm{s}$; (c) the third critical speed of $2300 \mathrm{rad} / \mathrm{s}$. 


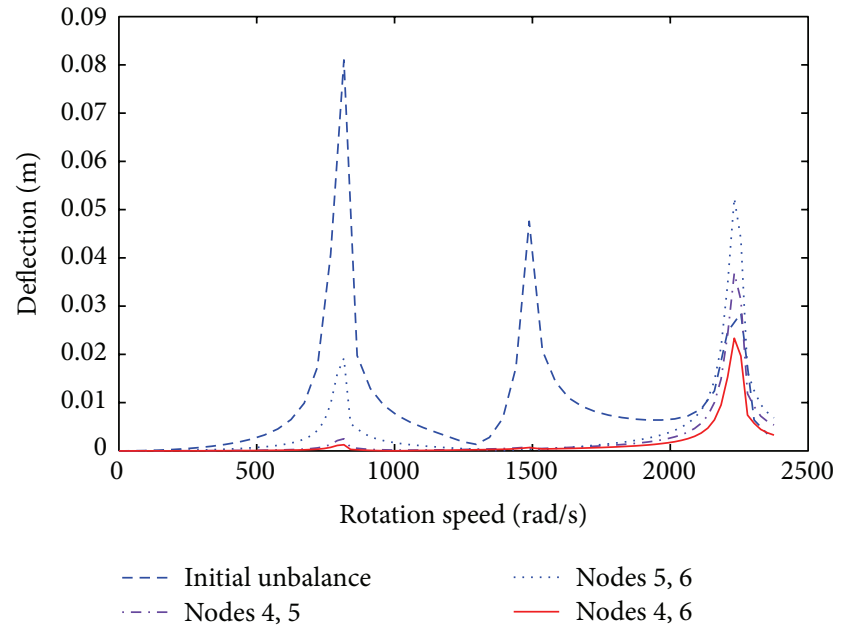

(a)

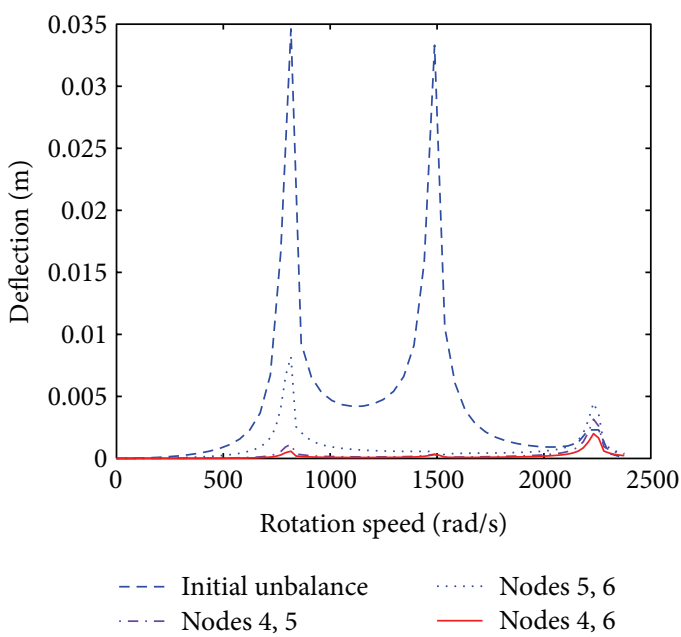

(b)

FIGURE 7: Transient deflection response versus speed of rotation with balancing (-) and without correction mass (- - -): (a) node 4, (b) turbine disk 1 , node 7 .

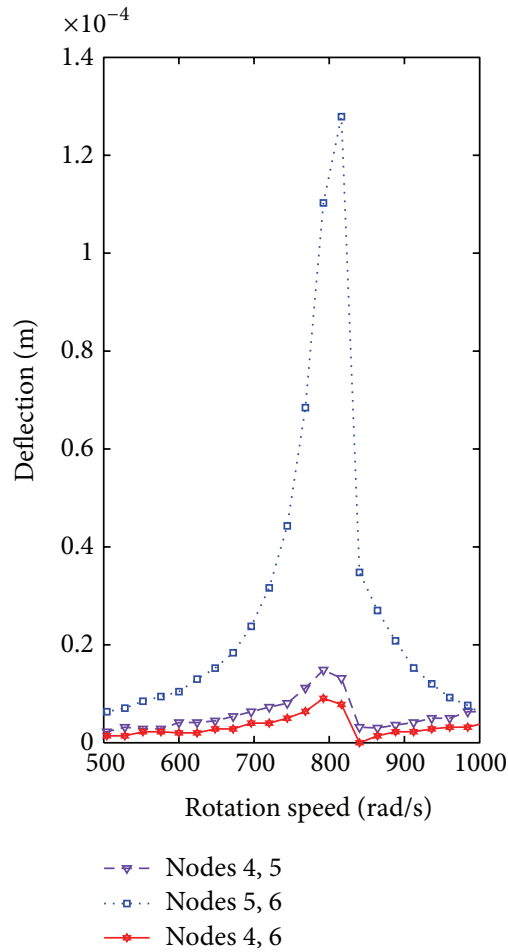

(a)

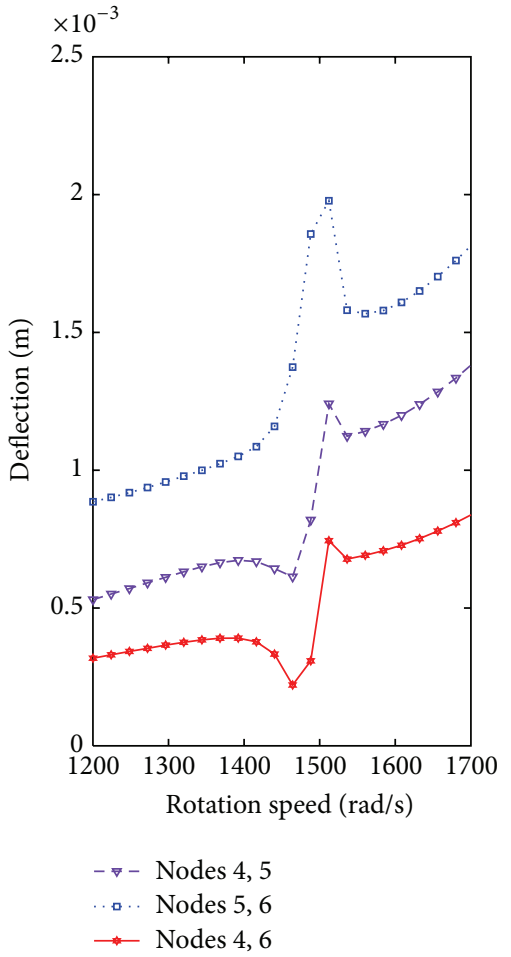

(b)

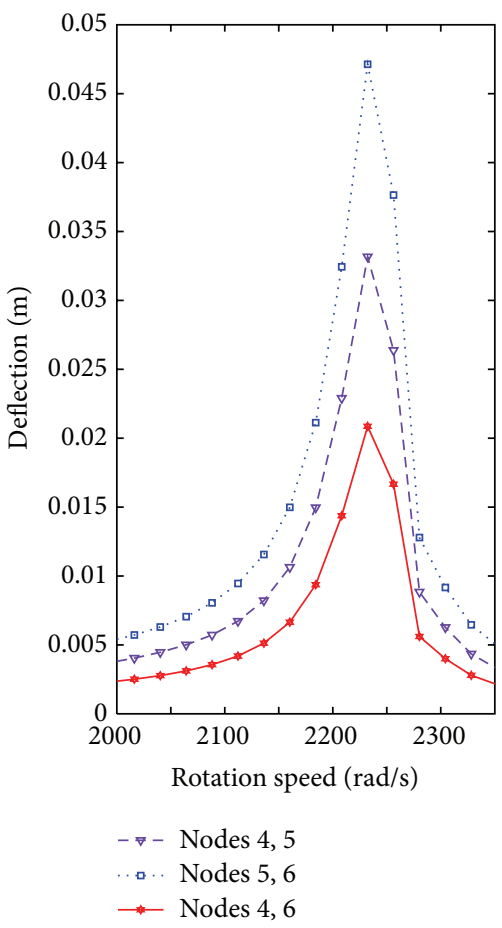

(c)

FiguRE 8: Transient resonance peak response versus speed of bearing 1 (node 2) with balancing (-) and without correction mass (- - -): (a) first critical speed, (b) second critical speed, and (c) third critical speed.

$\alpha_{k}$ : Phase angle of unbalanced rotor at $k$ th run test

$\theta_{k}$ : Angular position of trial weight at $k$ th run test $\gamma$ : Influence coefficient between measuring plane and balancing plane

$\beta$ : Phase coefficient between measuring plane and balancing plane
$R_{k i j}: j$ th modal dynamic deflection on plane $i$ at $k$ th run test

$\mathbf{I}_{i j}$ : $j$ th modal influence coefficient on plane $i$

$\mathbf{W}_{i j}$ : $j$ th modal correction weight on balancing plane $i$

$m_{i}$ : Mass on the $i$ th balancing plane 


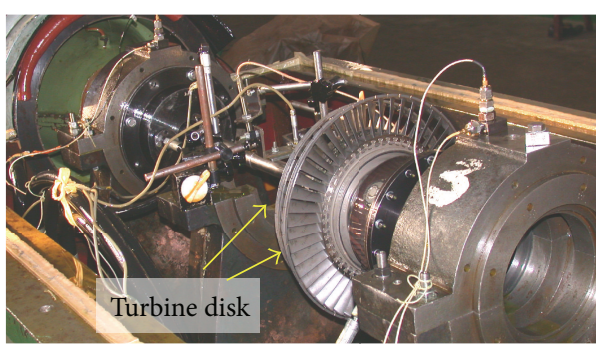

(a)

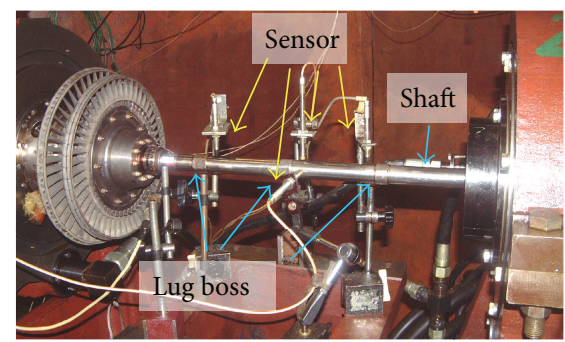

(b)

FIGURE 9: The experimental test turbine (a) rotor mounted on vibration generator and (b) close view of lug boss and sensor.
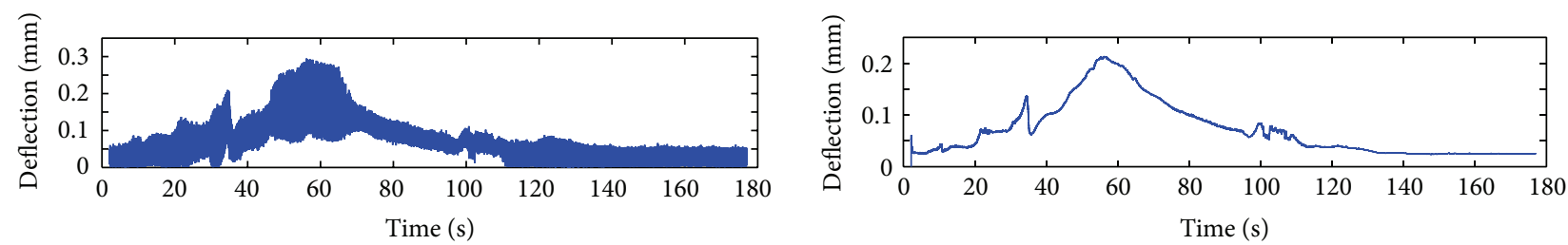

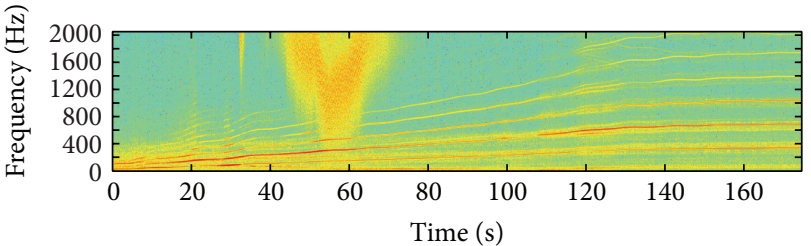

(a)

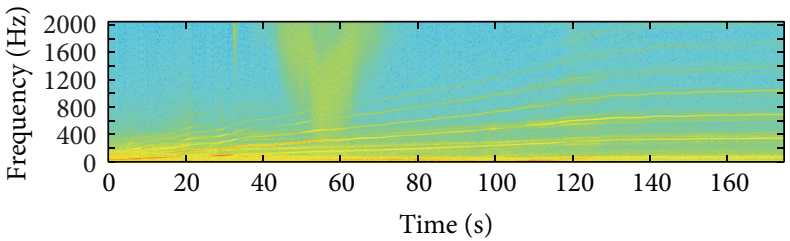

(b)

FIGURE 10: An initial run-up current characteristic (node 5) for the run-up case by STFT (a) in former filtering and (b) after filtering.

$e_{i}$ : Eccentricity ratio on the $i$ th balancing plane

$\dot{\varphi}$ : Spin velocity

$\ddot{\varphi}$ : Spin angular acceleration

M, C, K: Mass matrix, damping matrix, and stiffness matrix of the rotor, respectively.

\section{B. Main Parameters of the Academic Rotor Model}

Shaft

Young's modulus: $E=2.1 \times 10^{11} \mathrm{~N} / \mathrm{m}^{2}$

Length: $l_{1}=l_{6}=0.01 \mathrm{~m}, l_{2}=0.16 \mathrm{~m}, l_{3}=0.22 \mathrm{~m}$, and $l_{4}=l_{5}=0.18 \mathrm{~m}$

Diameter: $d=0.02 \mathrm{~m}$

Mass density: $\rho=7800 \mathrm{~kg} / \mathrm{m}^{3}$

The Poisson ratio: $\kappa=0.3$.

Disk

Diameter: $D_{1}=D_{2}=D_{3}=0.2 \mathrm{~m}$

Thickness: $H=0.03 \mathrm{~m}$

Viscous damping: $c_{1}=c_{2}=c_{3}=60 \mathrm{~N} \cdot \mathrm{s} / \mathrm{m}$

Mass density: $\rho=7800 \mathrm{~kg} / \mathrm{m}^{3}$
Initial unbalance mass: $\mathbf{T}_{01}=51.5 \mathrm{~g} \cdot \mathrm{cm} \angle 45^{\circ}, \mathbf{T}_{02}=$ $36.75 \mathrm{~g} \cdot \mathrm{cm} \angle 60^{\circ}$, and $\mathbf{T}_{03}=29.41 \mathrm{~g} \cdot \mathrm{cm} \angle 144^{\circ}$.

Bearing

Stiffness: $k_{1 x}=k_{1 y}=5.5 \times 10^{5} \mathrm{~N} / \mathrm{m}$ and $k_{2 x}=k_{2 y}=$ $5.0 \times 10^{5} \mathrm{~N} / \mathrm{m}$

Damping: $C_{1 x}=C_{2 x}=C_{1 y}=C_{2 y}=30 \mathrm{~N} \cdot \mathrm{s} / \mathrm{m}$.

\section{Conflict of Interests}

The authors declare that there is no conflict of interests regarding the publication of this paper.

\section{Acknowledgments}

This work has been supported by the research projects Aeronautical Science Foundation of China (no. 2013ZB08001) and National Natural Science Foundation of China (11272257). This support is gratefully acknowledged.

\section{References}

[1] J. M. Tessarzik, R. H. Badgley, and W. J. Anderson, "Flexible rotor balancing by the exact point-speed influence coefficient method," Journal of Engineering for Industry, vol. 94, no. 1, pp. 148-158, 1974. 
[2] Y. S. Shin and L. D. Santiago, "Surface ship shock modeling and simulation: two-dimensional analysis," Shock and Vibration, vol. 5, no. 2, pp. 129-137, 1998.

[3] Y. Kang, T.-W. Lin, Y.-J. Chang, Y.-P. Chang, and C.-C. Wang, "Optimal balancing of flexible rotors by minimizing the condition number of influence coefficients," Mechanism and Machine Theory, vol. 43, no. 7, pp. 891-908, 2008.

[4] J. W. Lund and J. Tonnesen, "Analysis and experiments on multiplane balancing of a flexible rotors," Journal of Engineering for Industry ASME, vol. 94, no. 1, pp. 233-242, 1972.

[5] T. P. Goodman, "A least-square method for computing balance corrections," Journal of Engineering for Industry, vol. 86, no. 3, pp. 273-279, 1964.

[6] Q. Wang and F. Wang, "A new vibration mechanism of balancing machine for satellite-borne spinning rotors," Chinese Journal of Aeronautics, vol. 27, no. 5, pp. 1318-1326, 2014.

[7] A. Chakraborty, "Dynamic balancing in NMR double rotor system," Spectrochimica Acta, Part A: Molecular and Biomolecular Spectroscopy, vol. 56, no. 14, pp. 2725-2727, 2000.

[8] A. Vania and P. Pennacchi, "Experimental and theoretical application of fault identification measures of accuracy in rotating machine diagnostics," Mechanical Systems and Signal Processing, vol. 18, no. 2, pp. 329-352, 2004.

[9] J. K. Sinha, A. W. Lees, and M. I. Friswell, "Estimating unbalance and misalignment of a flexible rotating machine from a single run-down," Journal of Sound and Vibration, vol. 272, no. 3-5, pp. 967-989, 2004.

[10] G. N. D. S. Sudhakar and A. S. Sekhar, "Identification of unbalance in a rotor bearing system," Journal of Sound and Vibration, vol. 330, no. 10, pp. 2299-2313, 2011.

[11] R. Whalley and A. Abdul-Ameer, "Contoured shaft and rotor dynamics," Mechanism and Machine Theory, vol. 44, no. 4, pp. 772-783, 2009.

[12] B. Xu and L. Qu, "A new practical modal method for rotor balancing," Proceedings of the Institution of Mechanical Engineers, Part C: Journal of Mechanical Engineering Science, vol. 215, no. 2, pp. 179-190, 2001.

[13] R. Tiwari and A. Chougale, "Identification of bearing dynamic parameters and unbalance states in a flexible rotor system fully levitated on active magnetic bearings," Mechatronics, vol. 24, no. 3, pp. 274-286, 2014.

[14] R. Ben-Ari and A. Rosen, "Mathematical modelling of a helicopter rotor track and balance: results," Journal of Sound and Vibration, vol. 200, no. 5, pp. 605-620, 1997.

[15] F. Sève, M. A. Andrianoely, A. Berlioz, R. Dufour, and M. Charreyron, "Balancing of machinery with a flexible variablespeed rotor," Journal of Sound and Vibration, vol. 264, no. 2, pp. 287-302, 2003.

[16] I. Chatzisavvas and F. Dohnal, "Unbalance identification using the least angle regression technique," Mechanical Systems and Signal Processing, 2014.

[17] R. E. D. Bishop and G. Parkinson, "On the isolation of modes in the balancing of flexible shafts," Preceedings of the Institution of Mechanical Engineers, vol. 177, pp. 407-426, 1963.

[18] W. Kellenberger, "Should a flexible rotor be balanced in $\mathrm{N}$ or $(\mathrm{N}+2)$ planes?" Journal of Manufacturing Science and Engineering, vol. 94, no. 2, pp. 548-558, 1972.

[19] B. G. Bykov, "Auto-balancing of a rotor with an orthotropic elastic shaft," Journal of Applied Mathematics and Mechanics, vol. 77, no. 4, pp. 369-379, 2013.
[20] K. Gjika and R. Dufour, "Rigid body and nonlinear mount identification: application to onboard equipment with hysteretic suspension," Journal of Vibration and Control, vol. 5, no. 1, pp. 75-94, 1999. 

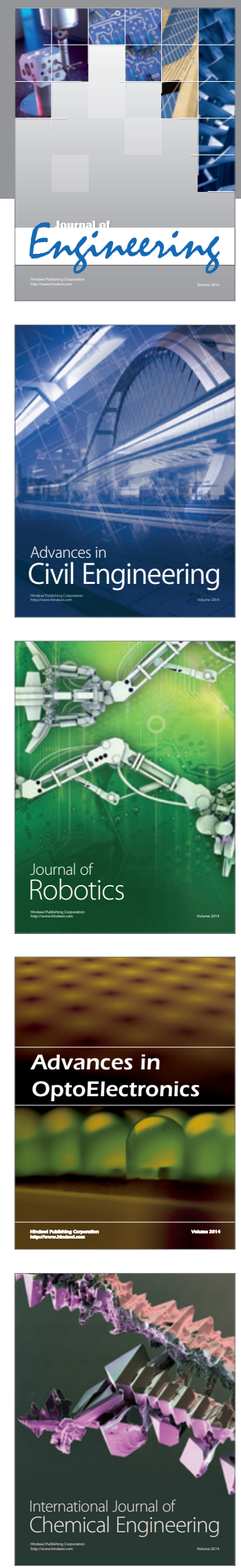

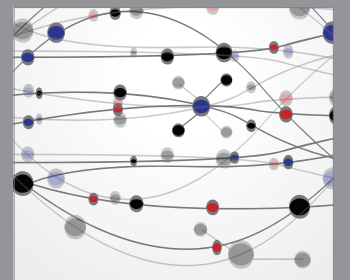

The Scientific World Journal
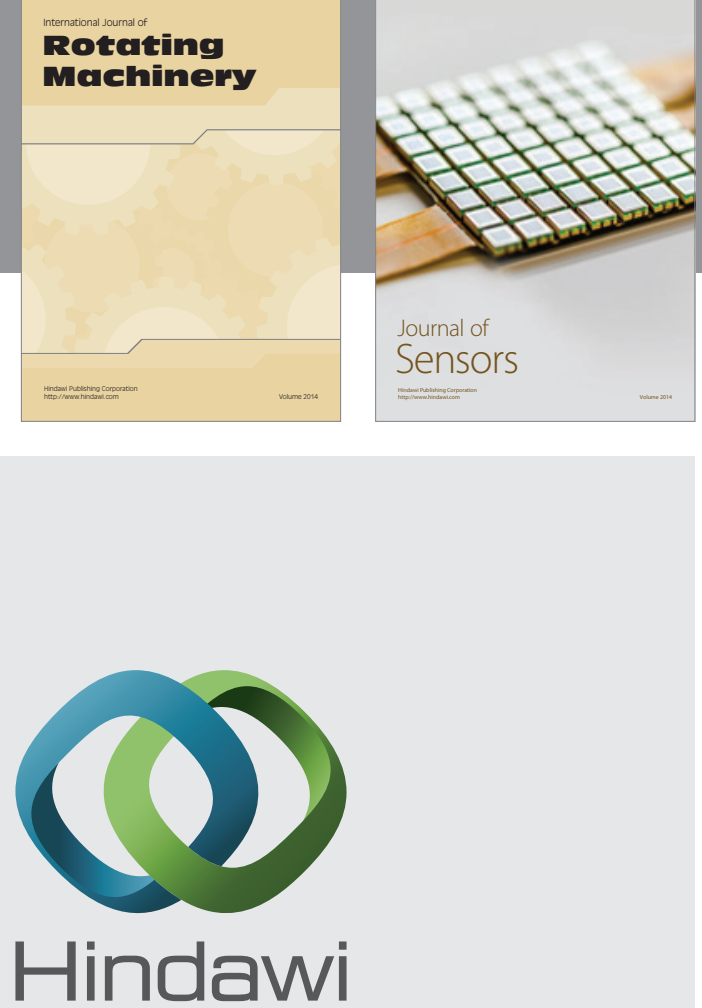

Submit your manuscripts at http://www.hindawi.com
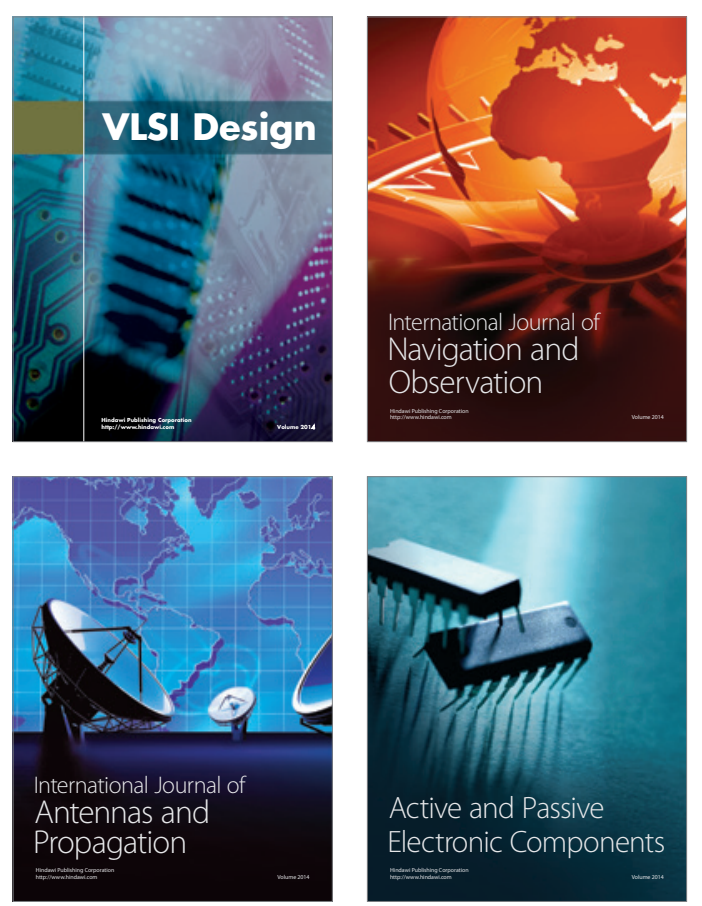
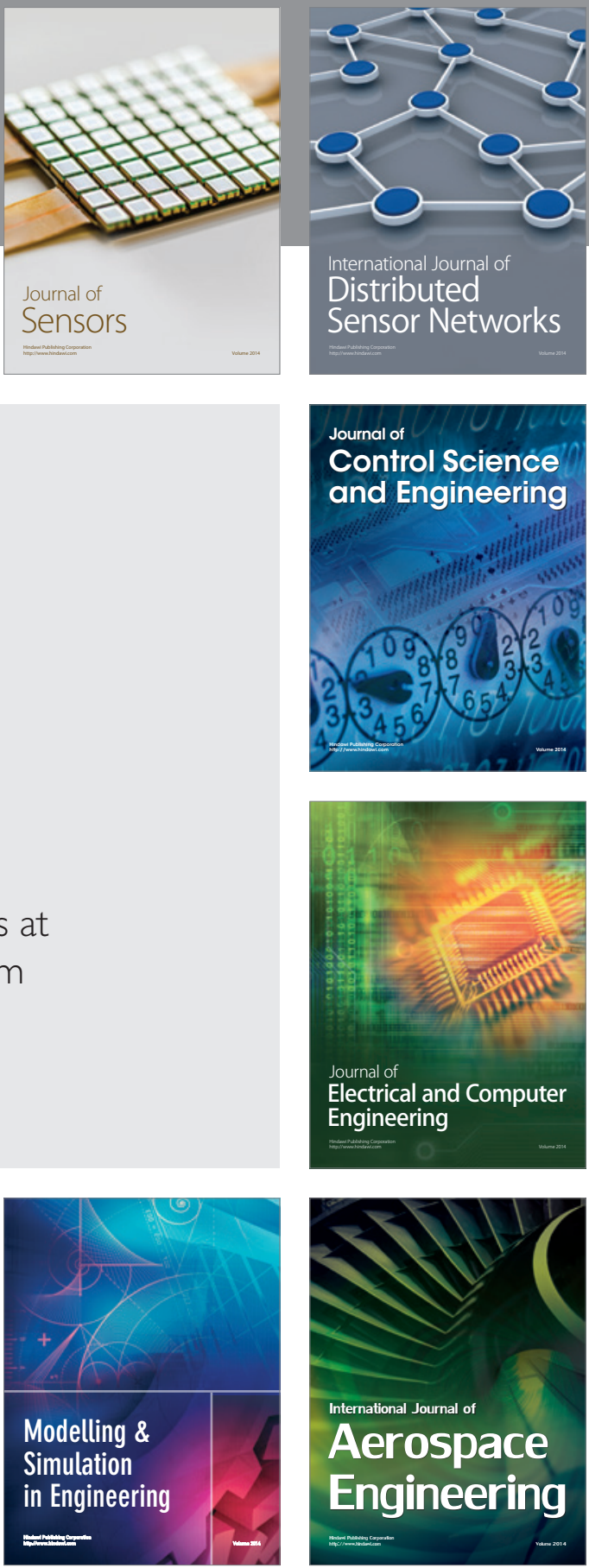

Journal of

Control Science

and Engineering
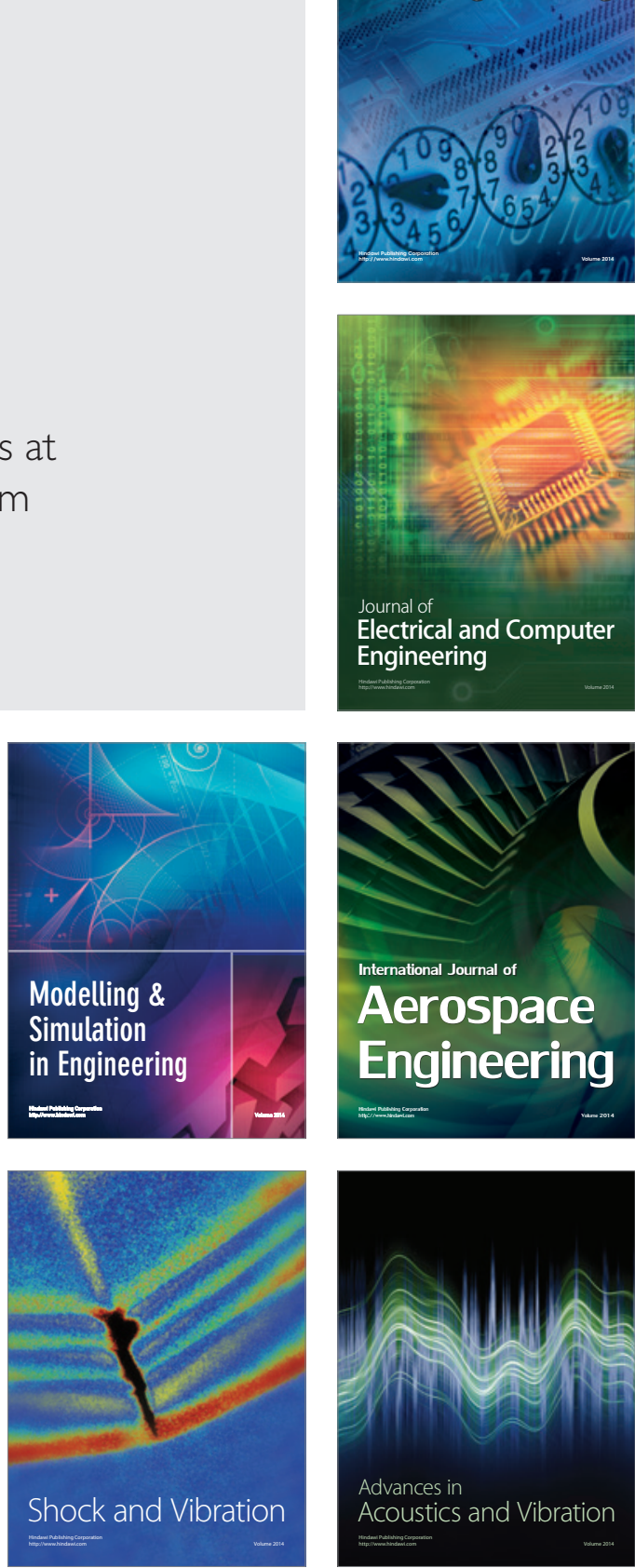